cient of friction. For soft powders (low rate of strain hardening) the coefficient of friction reaches a maximum at a higher compacting pressure than for hard powders.

5. For a die with smooth interior wall, frictional shear stresses may be reduced to practically zero by the use of wall lubricants.

6. Because of elastic deformation of a die during pressing, rigidity rather than strength is a necessary criterion for die design. Elastic bulging of a die results in the formation of laminar cracks.

\section{References}

1. H. Unckel: Mechanical Properties of Sintered Iron for Porous Bearings. Arch. Eisenhüttenwesen (1944) 18, 5-6, p. 125.

2. R. P. Seelig: Introduction to Seminar-Review of Literature on the Pressing of Metal Powders (with Discussion). Trans. AIME (1947) 171, 506. Metals Tech. Aug. 1947. TP 2236.

3. R. Kamm, M. Steinberg and J. Wulff: Plastic Deformation in Metal Powder Compacts. Trans. AIME (1947) 171, 439. Metals Tech. Feb. 1947. TP 2133.

4. E. von Siebel: Plastic Forming of Metals III. Investigation of Distribution of Deformation and Stress in Drawing, Pressing and Piercing. Steel (Apr. 9 and Mar. 10,1934 ).

5. P. Duwez and L. Zwell: Pressure Distribution in Compacting Metal Powders. Trans. AIME 185, 137.
Jnl. of Met., Feb. 1949.

6. S. Timoshenko: Strength of Materials, Part II. D. Van Nostrand Co. (1941).

7. C. W. MacGregor and L. F. Coffin, Jr.: Approximate Solutions for Symmetrically Loaded Thickwalled Cylinders. Jnl. Appl. Mech. A.S.M.E. (1947) 4. A-301.

8. R. Kamm, M. Steinberg and J. Wulff: Lead Grid Study of Metal Powder Compaction. Trans. AIME (1949) 180, 694. Metals Tech. Dec. 1948, TP 2487.

9. E. R. Holiday: Spectrophotometry of Proteins I. Biochem. Jrl. (1936) 30, 1785.

10. P. D. Crout: A Short Method for Evaluating Determinants and Solving Systems of Linear Equations with Real or Complex Coefficients. Trans. A.I.E.E. (Mar. 1942) 60

\title{
Rectangular Hysteresis Loops of Co-Ni-Fe Alloys
}

\section{R. A. CHEGWIDDEN*}

In view of the current interest in magnetic materials having rectangular hysteresis loops, as for example those obtained with the grain oriented 50 nickel 50 iron alloys, $\dagger$ we wish to call attention again to the results obtainable with the perminvar (Co-Ni-Fe) alloys heat treated in a magnetic field.

Data taken from direct current measurements made prior to and during World War II give the typical values shown below for two of the perminvar alloys. Fig 1 and 2 show the hysteresis loops for these samples.

The first sample above consisted of small rings punched from 0.014 in. sheet stock. These rings were heat treated at $1000^{\circ} \mathrm{C}$ for one hour in a hydrogen atmosphere and then cooled with the furnace to $750^{\circ} \mathrm{C}$ at which point they were subjected to a magnetic field of 15 oersteds maintained during cooling to room temperature. The molybdenum perminvar sample consisted of a spirally wound core of $0.001 \mathrm{in}$. tape. The heat treatment was the same except that box annealing methods were used and no hydrogen atmosphere was employed. Even better properties might be expected using hydrogen. The heat treating temperatures and cooling rates are not critical. Rectangular hysteresis loops produced in other perminvar alloys by heat treatment in a magnetic field were described earlier. ${ }^{1,2}$

Properties similar to those described

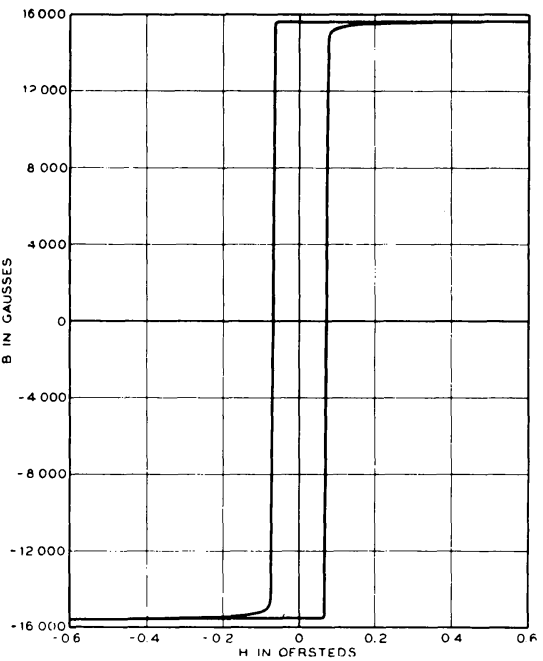

FIG 1-Hysteresis loop for 0.014 in. perminvar rings (43 $\mathrm{Ni} 34 \mathrm{Fe} 23 \mathrm{Co}$ ) heat treated in a magnetic field.

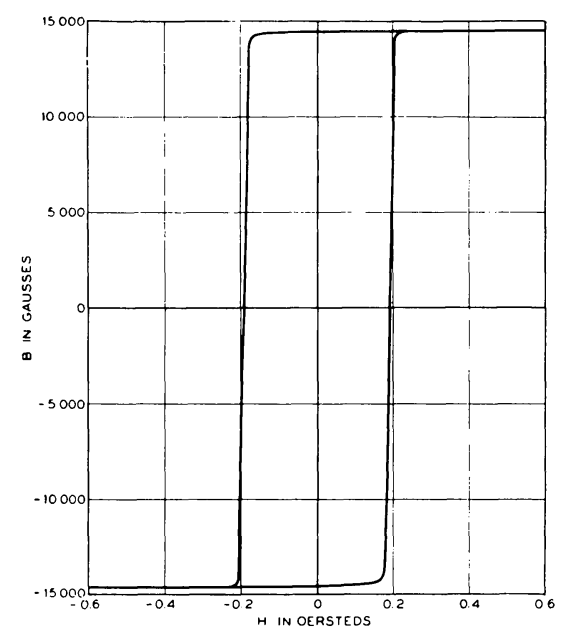

FIG 2-Hysteresis loop for 0.001 in. molybdenum perminvar tape core $(34 \mathrm{Ni}$ $34 \mathrm{Fe} 29 \mathrm{Co} 3 \mathrm{Mo}$ ) heat treated in a magnetic field.

\begin{tabular}{|c|c|c|c|c|c|c|c|}
\hline Nominal Composition & Thickness & $\mathrm{B} \max$ & $\mathrm{B}_{\mathrm{r}}$ & $\mathrm{B}_{\mathrm{r}} / \mathrm{B}_{\max }$ & $\mathrm{He}_{\mathrm{c}}$ & $\underset{\mu \max }{\text { Approx. }}$ & $\rho$ \\
\hline $\begin{array}{l}43 \mathrm{Ni} 34 \text { Fe } 23 \text { Co } \\
34 \mathrm{Ni} 34 \text { Fe } 29 \text { Co } \mathrm{C}_{3} \mathrm{Mo}\end{array}$ & $\begin{array}{l}0.014 \text { in. } \\
0.001 \text { in. }\end{array}$ & $\begin{array}{l}15650 \\
15200\end{array}$ & $\begin{array}{l}15600 \\
14500\end{array}$ & $\begin{array}{l}0.995 \\
0.955\end{array}$ & $\begin{array}{l}0.07 \\
0.19\end{array}$ & $\begin{array}{r}150,000 \\
72,000\end{array}$ & $\begin{array}{l}20 \\
52\end{array}$ \\
\hline
\end{tabular}

$B_{\max }=$ flux density in gausses at $H=20$ oersteds

$\mathrm{B}_{\mathrm{r}}=$ residual flux density in gausses

$\mathrm{H}_{\mathrm{c}}=$ coercive force in oersteds

$\mu \max =$ maximum permeability

$\rho=$ resistivity in microhm-cm

above are realized in perminvars manufactured by conventional methods. Drastic cold working which in practice limits the final thickness and is gen-

Technical Note 21E. Manuscript received May 31, 1949.

* Magnetics Research Dept., Bell Telephone Laboratories.

† Orthonol, Orthonik, Deltamax and similar materials.

1 References are at the end of the paper. erally expensive may thus be avoided. This information may be of interest to those concerned with magnetic alloys and the development of contact rectifiers, magnetic amplifiers and so on.

\section{References}

1. G. A. Kelsall: Physics. 5, 169-172, June, 1934.

2. R. M. Bozorth, J. F. Dillinger: Physics 6, 279-284, Sept., 1935. 